\title{
Design and Fabrication of Staircase for Power Generation by Using Pneumatic Cylinders
}

\author{
Vaibhav Bante $^{1}$, Vaibhav Nimgade ${ }^{2}$, Ashish Hatile ${ }^{3}$, Ram Walthare ${ }^{4}$, Prof. Suhas Wankhede ${ }^{5}$ \\ 1,2,3,4 Students, ${ }^{5}$ Asst. Professor, Wainganga college of engineering and management, Nagpur ,India
}

Published on: 07 July, 2021

\begin{abstract}
Whenever people walk on stairs, they loss some of their energy, we have design such a mechanism in which we have used this waste energy to generate electricity. Staircase electricity generation using pneumatic cylinders. There were many attempts in the past piezoelectric materials etc. But all of them proved very costly and were not practically feasible in day-today real life. The persons, who are walking on staircase are applying the impact force or thrust on the spring loaded stair case steps which is further connected with pneumatic cylinder. This impact pressure or walking energy can be utilized to generate electricity through continuous compression and release of air through pneumatic cylinder can be stored in a tank and this high pressure air is released through nozzle into a turbine due to which near about $12 v$ of electricity is generated which is sufficient to glow a LED lights.
\end{abstract}

Keywords-- pneumatic cylinders, material.

\section{I- INTRODUCTION}

$\boldsymbol{I}_{n}$ n today's fast moving world energy demands \& use is even increasing to cope up with these even increasing energy demands our need to derives various mechanism those are capable to generate electricity. The staircase electricity generator is specially planned to design and fabricate the conversion unit for utilizing the available unconventional energy source. That is tremendously available energy in low intensity with ample quantity can be utilized. This source of power can be used at the station building, platform and waiting rooms. Also by accumulating this low intensity electricity in Batteries, it can be supplied to the commercial complexes or shopping complexes near by the railway station, big shopping Malls or in Big villages or in towns where there is scarcity of electric supply.

1. Investigation of Generation of electricity using foot step(2015), Sibabrata Mohanty, Sansank Shankar Panda, Research scholar, Department of Indusrial Engineering,G.I.E.T, Gunupur. Rayagada, India.

2. Proposed method of Foot Step Power Generation Using Piezo-Electric Sensor(2015), Mr. Adhithan, K. Vingesh, M. Manikandan, Assitant Professor, Department of EEE.

3. Footstep Power Generation Using Piezo-Electric Transducers, Kiran Boby, Alena Paul, Anumol. C.V, Joshnie Ann Thomas, Nimisha K.K

4. Power Harvesting by Using Human Footstep, Prabaharan R, Jayaramaprakash A, Vijay Anand.

5. Power Generation Footstep, Shiraz Afzal, Farrukhhafeez

6. Electricity Generation Due to Vibration of Moving Vehicles Using Piezoelectric Effect, MuktiNath Gupta, Suman and S.K. Yadav. 


\section{International Journal of Innovations in Engineering and Science, www.ijies.net}

\section{II- METHOLOGY}

Impact Force Or Trust Force Developed Due To Walking On Foot

Impact Force Converts In Linear Motion Of Pneumatic Cylinders Into High Air Pressure.

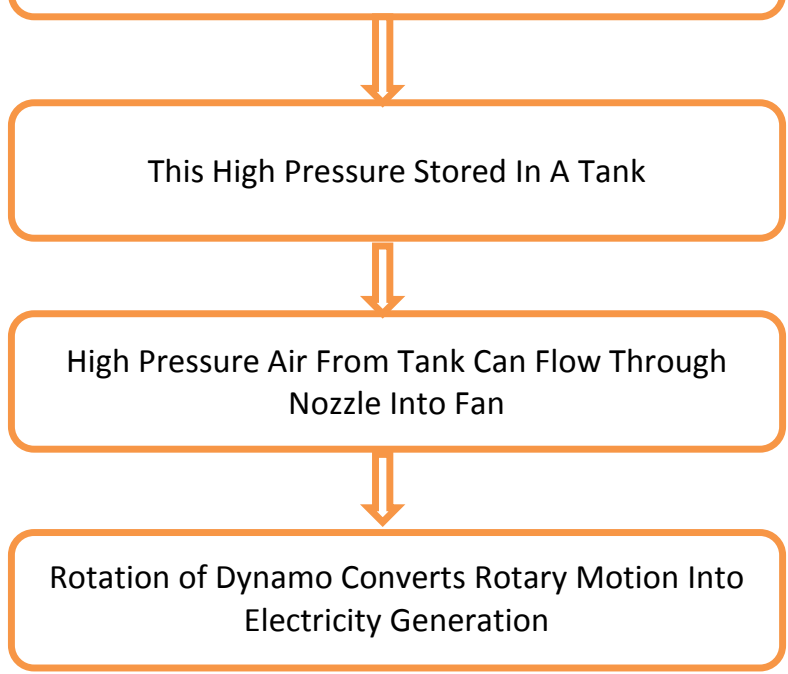

\section{Components}

1) Pneumatic cylinder.

2) Pneumatic pipe.

3) Air tank.

4) Generator motor.

5) MS frame.

6) Electronic circuit.

7) Battery.

\section{Pneumatic cylinder}

- Pneumatic cylinders (sometim4es known as air cylinders) are mechanical devices which use the power of compressed gas to produce a force in a reciprocating linear motion.

- Like hydraulic cylinders, something forces a piston to move in the desired direction. The piston is a disc or cylinder, and the piston rod transfers the force it develops to the object to be moved. Engineers sometimes prefer to use pneumatics because they are quieter, cleaner, and do not require large amounts of space for fluid storage.

- Because the operating fluid is a gas, leakage from a pneumatic cylinder will not drip out and contaminate the surroundings, making pneumatics more desirable where cleanliness is a requirement.

- Due to the forces acting on the cylinder, the piston rod is the most stressed component and has to be designed to withstand high amounts of bending, tensile and compressive forces. Depending on how long the piston rod is, stresses can be calculated differently. If the rods length is less than 10 times the diameter, then it may be treated as a rigid body which has compressive or tensile forces acting on it.

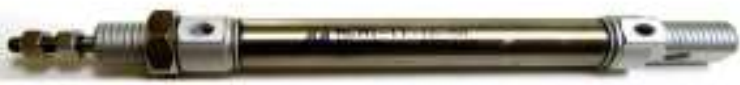

\section{Pneumatic pipe}

- Pneumatic tubes (or capsule pipelines; also known as Pneumatic Tube Transport or PTT) are systems that propel cylindrical containers through a network of tubes by compressed air or by partial vacuum They are used for transporting solid objects, as opposed to conventional pipelines, which transport fluids. Pneumatic tube networks gained acceptance in the late 19th and early 20th centuries for offices that needed to transport small, urgent packages (such as mail or money) over relatively short distances (within a building, or, at most within a city). Some installations grew to great complexity, but were mostly superseded. In some settings, such as hospitals, they remain widespread and have been further extended and developed in recent decades.

- A small number of pneumatic transportation systems were also built for larger cargo, to compete with more standard train and subway systems. However, these never gained popularity.
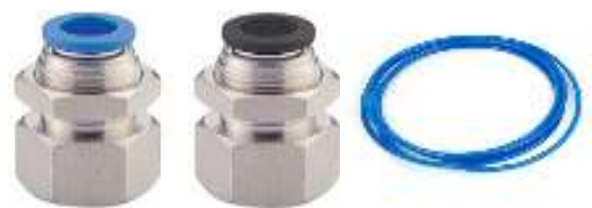

Air tank

- $\quad$ Air tank is made of MS sheet which is used for storing pressurized air which is compressed by pneumatic cylinder. 


\section{International Journal of Innovations in Engineering and Science, www.ijies.net}

\section{Generator motor}

- A motor-generator is a device for converting electric power to another form. Motor-generator sets are used to convert frequency, voltage, or phase of power. They may also be used to isolate electrical loads from the electrical power supply line. Large motorgenerators were widely used to convert industrial amounts of power while smaller motor-generators (such as the one shown in the picture) were used to convert battery power to higher DC voltages.

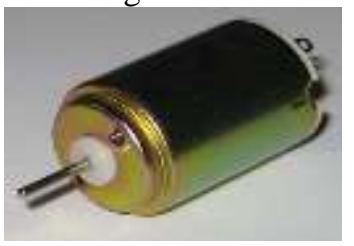

\section{Battery}

- An electric battery is a device consisting of one or more electrochemicalcells that convert stored chemical energy into electrical energy. Each cell contains a positive terminal, or cathode, and a negative terminal, or anode. Electrolytes allow ions to move between the electrodes and terminals, which allows current to flow out of the battery to perform work.

- Primary (single-use or "disposable") batteries are used once and discarded; the electrode materials are irreversibly changed during discharge. Common examples are the alkaline battery used for flashlights and a multitude of portable

devices. Secondary (rechargeablebatteries) can be discharged and recharged multiple times; the original composition of the electrodes can be restored by reverse current. Examples include the lead-acid batteries used in vehicles and lithium ion batteries used for portable electronics. Batteries come in many shapes and sizes, from miniature cells used to power hearingaids and wristwatches to battery banks the size of rooms that provide standby power for telephone exchanges and computer data centers.

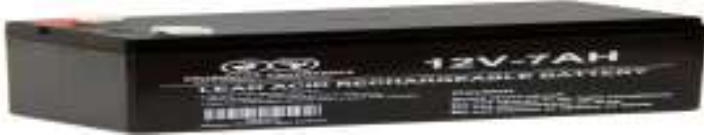

Applications
- $\quad$ Temples Like Tirupati, Shirdi Etc.

- $\quad$ Shopping Mall

- Jogging Parks

\section{Advantages}

- Non Conventional Source Of Energy

- Saving Of Coal And Water For Generating Electricity

- Eco Friendly, I.E. Pollution Free Electricity Generation

- Simple Mechanism

- Easy For Installation

- Easy For Maintenance

- Works Only When Someone Uses Stairs

\section{III- WORKING}

- The model consists of receiver tank with nonreturn valve, and outlet valve.

- Dial gauge is a pressure measuring device which is used to measure the pressure in the tank. The dial gauge is mounted on the receiver tank.

- In each staircase we have mounted two piston cylinder arrangement i.e. total six piston cylinder.

- These cylinders are connected to receiver tank via pneumatic pipes.

- A ATMEGA 16 controller is used to control the flow rate and supply the air with constant pressure without any fluctuations.

- Impact force on thrust develops due to walking on staircase

- This impact force converts linear motion of pneumatic cylinders into high pressure air

- This high pressure air is stored in tank

- High pressure air from tank can flow through nozzle into a fan

- Rotation of dynamo converts rotary motion into electricity generation.

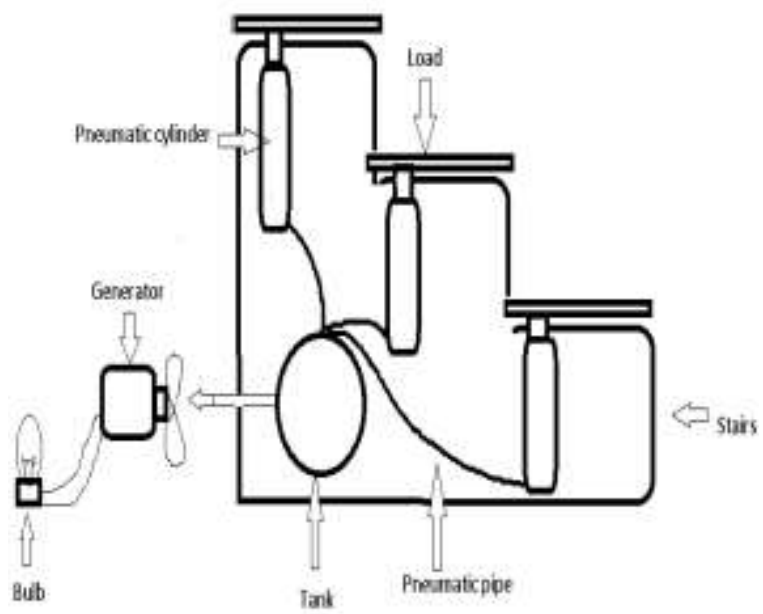

- Railway Station

- Airports 


\section{International Journal of Innovations in Engineering and Science, www.ijies.net}
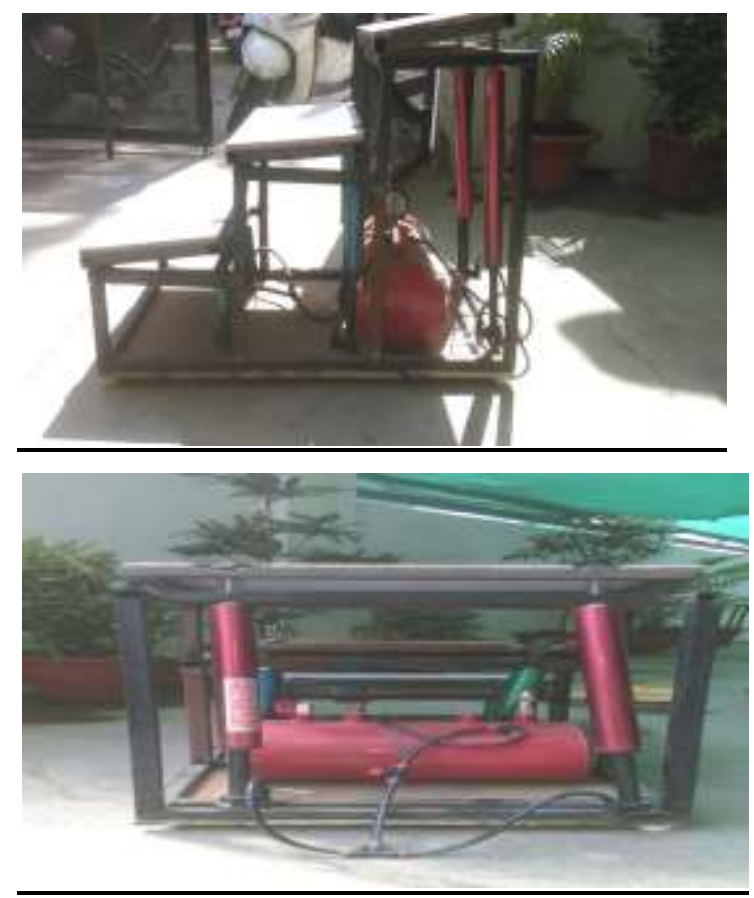

\section{IV- DESIGN \& CALCULATION}

Internal diameter of cylinder $=32 \mathrm{~mm}$

Height of cylinder $=30 \mathrm{~mm}$

Therefore,

Volume of air compressed in one stroke;

$$
\begin{aligned}
v & =\pi r^{2} h \\
& =(3.14 \times 16 \times 16 \times 30) \mathrm{mm} \\
& =24115.2 \mathrm{~mm}^{3}
\end{aligned}
$$

Volume of air displaced by one step;

$$
\begin{aligned}
& =2 \times 24115.2 \\
& =48230.4 \mathrm{~mm}^{3}
\end{aligned}
$$

Volume of air compressed by our model i.e. three steps;

$=3 \times 48230.4$

$=144691.2 \mathrm{~mm}^{3}$

Volume of tank $=\pi r^{2} h$

$$
\mathrm{d}=175 \mathrm{~mm}
$$

Therefore, $v=3.14 \times 87.5 \times$

$87.5 \times 305$

\section{$=7332390.6 \mathrm{~mm}^{3}$}

The tank will be fill in near about 50 footsteps.

\section{Body Design: -}

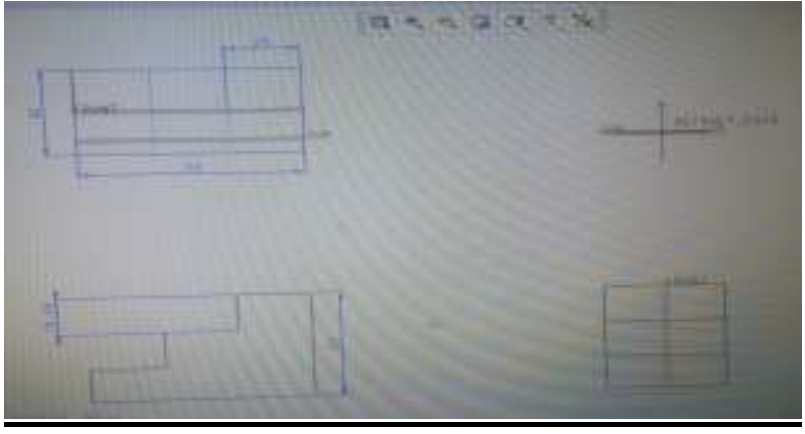

Fig..6 - Generative model of body via CREO

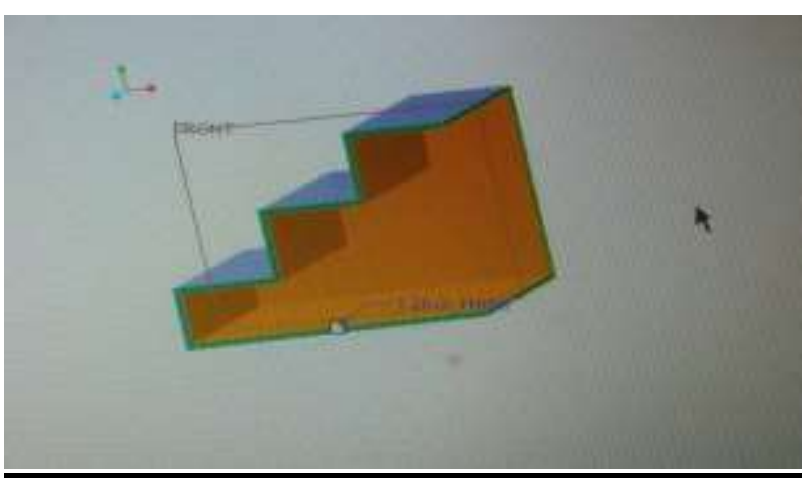

Fig. 7- Solid model of body via CREO

\section{Spring Design:}

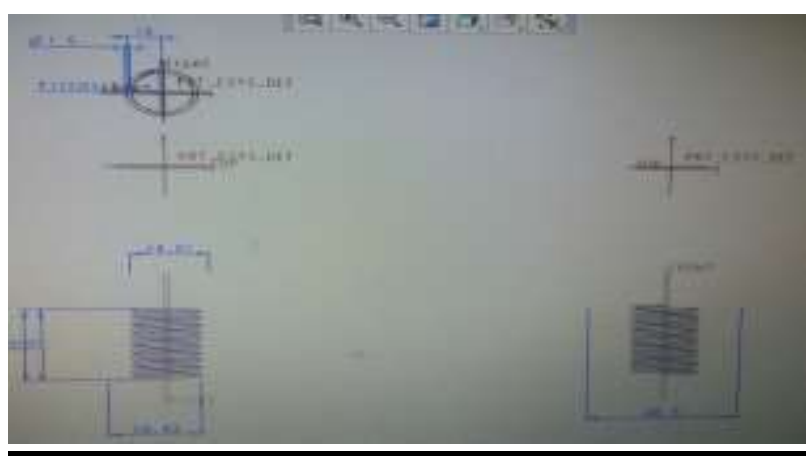

Fig..8- Generative drawing of spring via CREO

Stiffness of spring $=\frac{\text { force }}{\text { Deflection }}$

Where,

Force = Mass $\times$ gravity ---------------- $(\mathrm{g}=9.8$ $\mathrm{m} / \mathrm{s}^{2}$ )

$$
\mathrm{F}=80 \mathrm{Kg} \times 9.8 \mathrm{~m} / \mathrm{s}^{2}
$$

\section{$\mathrm{F}=784 \mathrm{~N}$}

Where, Deflection $=25 \mathrm{~mm}$ $-(0.025 \mathrm{~m})$

Therefore,

$$
K=\frac{784}{0.025}
$$




\section{International Journal of Innovations in Engineering and Science, www.ijies.net}

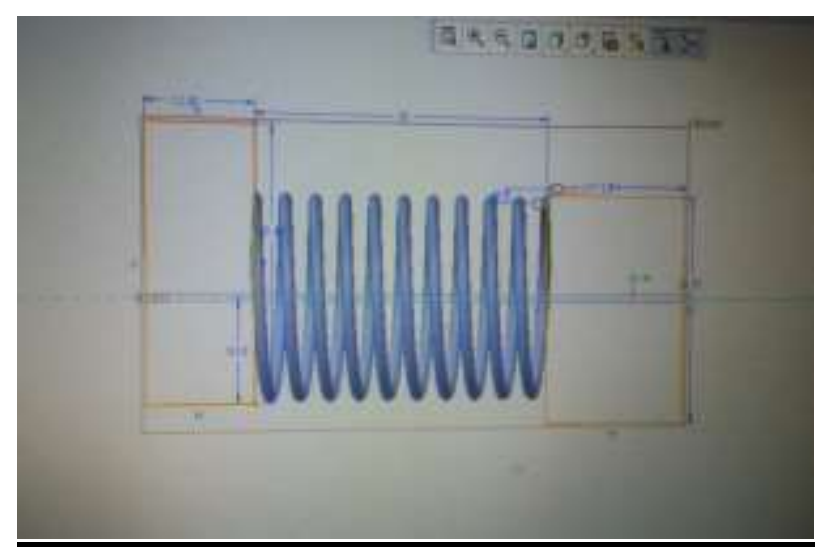

Fig. 9- 3D Model of Spring via CREO

\section{V- CONCLUSION}

- This method produces electricity with the help of piezoelectric elements that make use of the energy of human footsteps.

- The capacitor used in the circuit stores the charge for future applications. In order to increase the efficiency of the whole system if super capacitors are used in place of the conventional ones then more charge can be stored than the conventional ones.

- The super capacitors store and discharge energy without consuming much energy. Thus, the requirement of constant increase of power can bemet by installing these systems in heavily packed places. This will undoubtedly not only overcome the energy crises but also buildup a healthy surrounding.

- With the help of this system, we can overcome the load on fossil fuel, which uses for electric generation. It is more useful for today's circumstances where demand of electricity goes on increasing by using human effort. The overall system does not perform as much as more equipment. As it's input is freely available, so we can say that It is $100 \%$ profitable \& economical. As per our requirement, we can modify this system with its empirical relation to large extent.t, so It is easy to install at any crowdie space.

\section{REFERENCES}

[1] Staircase Power Generation Using Piezo-Electric Transducers, V. Prasannabalagi, R. Rakesh, S. Sairam and S. Mahesh.

[2] Footstep Power Generation Using Piezo-Electric Transducers, Kiran Boby, Alena Paul, Anumol. C.V, Joshnie Ann Thomas, Nimisha K.K

[3] Power Harvesting by Using Human Footstep, Prabaharan $R$, Jayaramaprakash A, Vijay Anand.
[4] Power Generation Footstep, Shiraz Afzal, Farrukhhafeez.

[5] Electricity Generation Due to Vibration of Moving Vehicles Using Piezoelectric Effect, MuktiNath Gupta, Suman and S.K. Yadav.

[6] Proposed Method of Foot Step Power Generation Using Piezo Electric Sensor, Mr.A.Adhithan, K.Vignesh, M.Manikandan

[7] Foot Step Power Generation Using Piezoelectric Material, Miss. MathaneNitashree V., Miss. SalunkheArati L, Miss. GaikwadSayali $S$.

[8] Power generation using foot step method. P.Balaji.

[9] Piezoelectric Generator Harvesting Bike Vibrations Energy to Supply Portable Devices. E. Minazara, D. Vasic and F. Costa.

[10] Piezoelectric and Magnetoelectric Thick Films for Fabricating Power Sources in Wireless Sensor Nodes, ShashankPriya,JunghoRyu, Chee-Sung Park, Josiah 